\title{
Invasive Lionfish Use a Diversity of Habitats in Florida
}

\section{Introduction}

Two species of lionfish (Pterois volitans and Pterois miles) are the first marine fishes known to invade and establish self-sustaining populations along the eastern seaboard of the United States. First documented off the coast of Florida in 1985, lionfish are now found along the Atlantic coast of the United States as well as in the Caribbean Sea and Gulf of Mexico (see map below). Although long-term effects of this invasion are not yet fully known, there is early evidence that lionfish are negatively impacting native marine life.

The lionfish invasion raises questions about which types of habitat the species will occupy in its newly invaded ecosystem. In their native range, lionfish are found primarily on coral reefs but sometimes are found in other habitats such as seagrasses and mangroves. This fact sheet documents the diversity of habitat types in which invasive lionfish have been reported within Florida's coastal waters, based on lionfish sightings recorded in the U.S. Geological Survey Nonindigenous Aquatic Species database (USGS-NAS).

\section{Habitats Observed}

Lionfish were reported in a wide diversity of habitats in Florida, including both artificial structures (bridges, canals, docks, derelict traps, and shipwrecks) and natural ecosystems (reefs, mudflats, and seagrasses).

Records were grouped according to 10 broad habitat categories: shoreline artificial, submerged artificial, natural reef, canal/channel, natural hardbottom, mangrove, mud or sand, seagrass, water surface, and rocks. Each of the categories included diverse habitat types. The shoreline artificial category, for example, included bridges, piers, jetties, and docks. Submerged artificial was an especially diverse category that included wrecks (ships of all sizes, airplanes, army tanks), traps (lobster, crab, derelict), concrete culverts, prefabricated erosion protection (PEP) reefs, concrete pilings, coral nurseries, data buoys/markers, metal boilers, discarded boat trailers, reef balls, bridge debris, and even the Aquarius undersea research station. These habitats include a combination of purposebuilt artificial structures intentionally placed on the ocean floor to attract sea life (reef balls, wrecks, PEP reefs); structures that are currently in use by government, academic, and non-governmental agencies (coral reef nursery, Aquarius habitat, data buoys/markers); fishing gear (both in use and derelict); and discarded debris (boat trailers, metal boilers).

\section{Records of Lionfish Sightings}

The records used to review lionfish habitats are from the USGS-NAS database, the national repository for non-native aquatic fishes in the United States. The database is publicly available online at http://nas.er.usgs.gov.

Records are spatially referenced and come from a variety of validated sources, including scientific literature, published and unpublished reports, museum specimens, personal communications, and databases from organizations such as Reef Environmental Education Foundation (REEF), the National Oceanic and Atmospheric Administration (NOAA), and Mote Marine Laboratory. Data are based primarily on opportunitistic observations, rather than $\mathbb{R Q}$ deliberate surveys. Therefore, the likelihood of reporting varies from place to place, and the resulting number of reports for a given area may not reflect the actual density of lionfish. For example, places with well-established dive operations and formal lionfish awareness programs are likely to have a greater number of reports.

This fact sheet includes data collected through December 2010 from 1,244 total lionfish records in the USGS-NAS database, which documents 3,106 individual fish. It was possible to assign habitat categories to 2,061 of these. Further habitat information was obtained for 246 lionfish caught as part of the 2010 Florida Keys lionfish derbies held by REEF. In total, habitat categories were assigned to 2,307 individual fish.

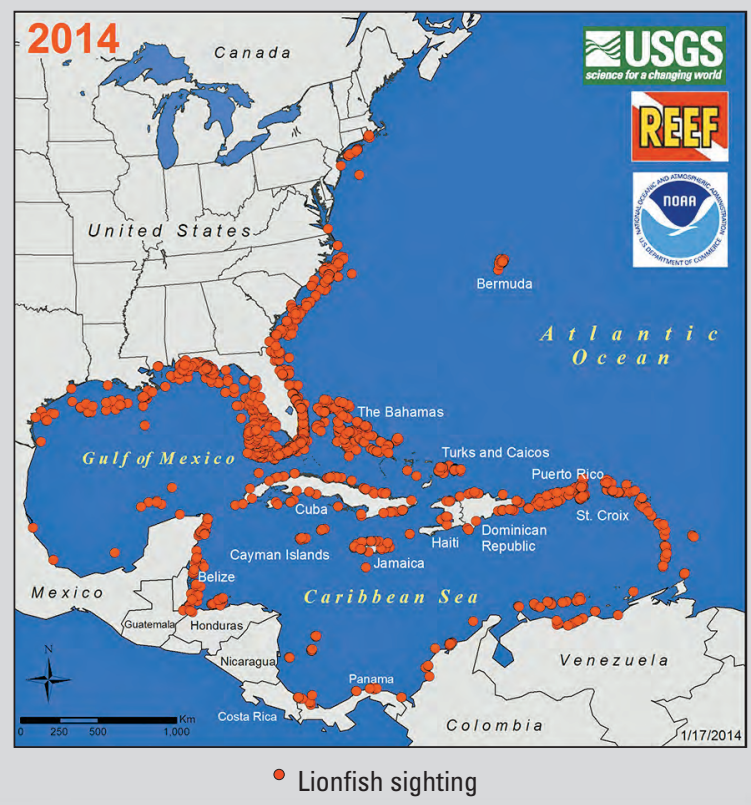




\section{Lionfish Habitat Types Based on Reports to USGS-NAS}
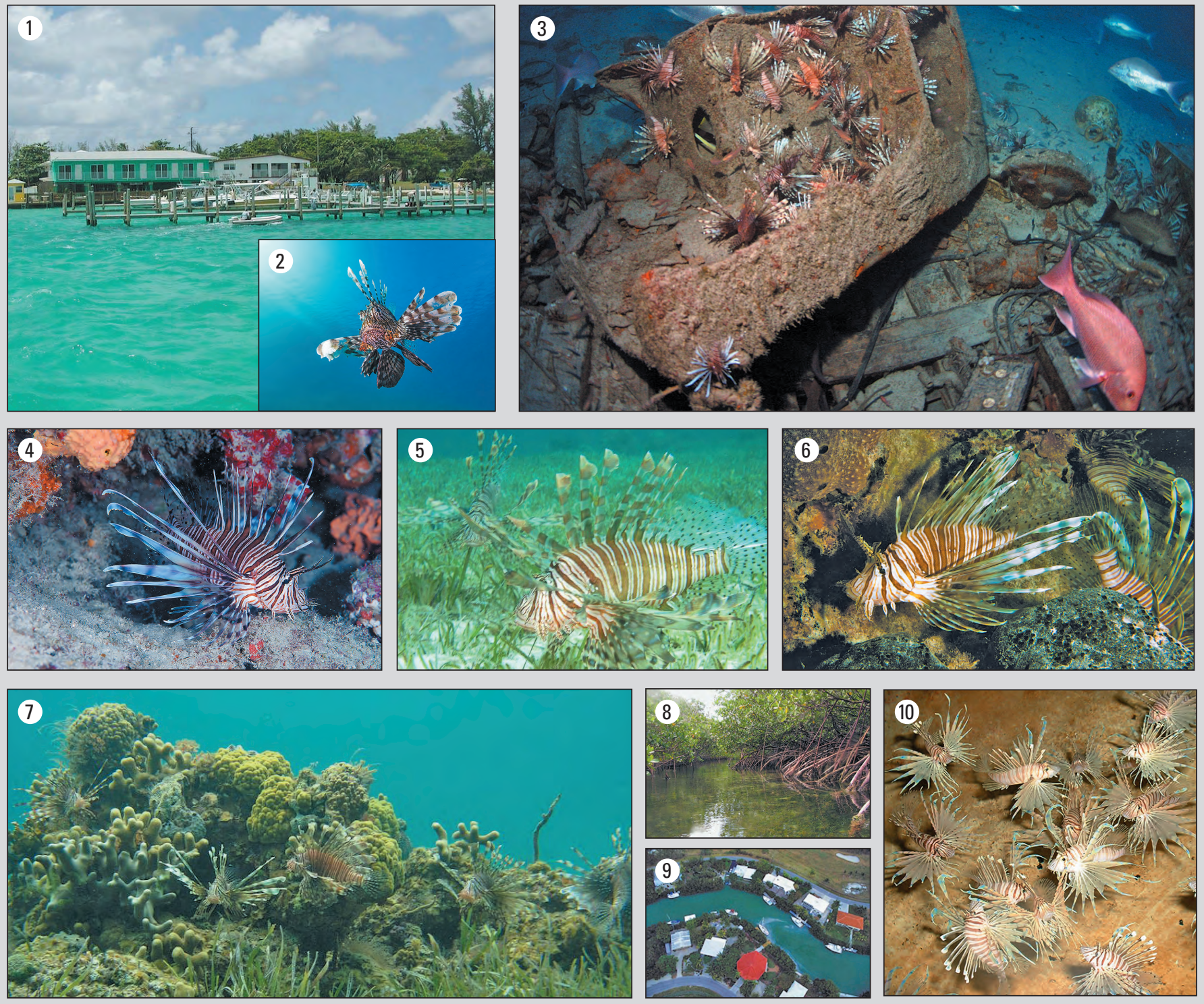

Number of sightings by habitat type: 1 Shoreline artificial-524 2 Water surface-1 3 Submerged artificial-851 4 Natural hardbottom-22 5 Seagrass-7 6 Rock-47 7 Natural reef-794 8 Mangrove-4 9 Canal-44 10 Mud or sand-13

\section{Conclusion: Lionfish Are Not Restricted to Reefs}

The sightings recorded in the USGS-NAS database reveal that lionfish have been observed in a wide variety of habitats throughout their invaded range in Florida. Though these data do not allow for a statistical comparison of lionfish densities among habitats, the data document the ubiquitous nature of lionfish habitat use. Further surveys to quantify lionfish densities among the various habitat types will advance scientific understanding of the lionfish use of habitats in its invaded range.

\section{How Can You Help?}

Report lionfish sightings at one of the following Web sites:

- USGS: http://nas.er.usgs.gov/SightingReport.aspx

- REEF: http://www.reef.org/programs/exotic/report

\section{For More Information}

USGS Lionfish Fact Sheet:

http://nas.er.usgs.gov/queries/FactSheet.aspx?speciesID $=963 \#$

REEF Lionfish Research Program Web page:

http://www.reef.org/lionfish

Field Guide to the Nonindigenous Marine Fishes of Florida: http://fl.biology.usgs.gov/Marine_Fish_ID/index.html

Pamela J. Schofield, Research Ecologist, U.S. Geological Survey, Southeast Ecological Science Center, 7920 NW 71st Street, Gainesville, FL 32653 U.S.A.; email: lionfish@usgs.gov

Lad Akins, Director of Special Projects, Reef Environmental Education Foundation, P.O. Box 246, Key Largo, FL 33037 U.S.A.; email: lad@reef.org 